Okajimas Fol. anat. jap., $40: 381-391,1965$

\title{
Adrenal Glands in Lactating Rats Bearing Hypothalamic Lesions
}

\author{
$\mathrm{By}$
}

\section{Toshitake Fujioka, Katuaki Ôta and Akira Yokoyama}

Laboratory of Veterinary Anatomy and Laboratory of Animal Breeding; Faculty of Agriculture, Nagoya University, Anzyo, Japan

It has been previously reported ( $\mathrm{Y}$ o k o y a m a and Ôta, 1959a and $b)$ that the lesions placed in the periventricular and the medial hypothalamic areas in lactating rats impaired oxytocin secretion selectively. Considerable amount of milk was obtained by oxytocin replacement in these rats, although the amount of milk was less than that obtained in normal lactating animals.

There has been a considerable body of evidence indicating the view that the adrenal corticoids were one of the critical factors for maintaining lactation in rats (Cow i e, 1961). Gale, Taleis nik, Friedman and M c Cann (1961) demonstrated direct relation between the adrenal size and lactational performance in lactating rats bearing lesions in median eminence.

An attempt was made to associate histological changes in adrenal glands with those in lactational performance in lactating rats bearing hypothalamic lesions, since changes in adrenal glands were presumed to reflect those in the secretory level of the gland.

\section{Material and Methods}

Both sides of adrenal glands of 54 Wistar strain lactating rats bearing hypothalamic lesions used in the previous studies ( $Y$ ok oy a m a and Ôta, 1959a, b and 1960) were removed immediately after the autopsy. They were freed from adherent tissues and weighed. Each side of the adrenal gland was fixed in Bou in's and $R$ eg a $u d$ 's solutions, respectively. Six $\mu$ paraffin sections were stained with Mallory's azan or PAS method.

Sham operated and hypothalamic lesioned animals which succeeded in rearing (Group 1) were killed on the 20th day of lactation. Animals bearing lesions which failed to rear their young (Group 
2) were mostly autopsied as soon as the failure was well established. Some of the lesioned, rearing-failed rats were replaced with 1.5 i. u. of oxytocin twice daily. They could rear their young and were killed generally on the 15th day of lactation (Group 3).

In an attempt to avoid bias, histological examinations were carried out without any previous information of lactational performance of the experimental animals.

\section{Results}

Weight of adrenal glands was illustrated in Table 1 . Since the weight of adrenal glands in sham operated rats was not significantly different from that of adrenal glands in rats which succeeded in rearing, data of the glands in sham operated rats were put into Group 1.

Table 1. Weight of adrenal glands in rats bearing hypothalamic lesions

\begin{tabular}{c|l|c|c}
\hline Group & Treatment and lactational performance & $\begin{array}{c}\text { No. of } \\
\text { animals }\end{array}$ & $\begin{array}{c}\text { Mean adrenal weight } \\
\text { (mg/100g body wt.) }\end{array}$ \\
\hline 1 & $\begin{array}{c}\text { lesioned, rearing-succeeded \& sham } \\
\text { operated }\end{array}$ & 20 & $25.4 \pm 0.8^{*}$ \\
\hline 2 & lesioned, rearing-failed & 15 & $31.2 \pm 2.1^{* *}$ \\
\hline 3 & lesioned, oxytocin-replaced & 10 & $30.1 \pm 1.6^{* *}$ \\
\hline
\end{tabular}

* S. E. of means

** Significantly different from Group $1(\mathrm{P}<0.02)$

Adrenal glands of Groups 2 and 3 were significantly heavier than those of Group 1. The difference in adrenal weight between Group 2 and Group 3 was not statistically significant.

On the basis of the histological appearance, adrenal glands were divided into the following two types. The adrenal cortex of the first type consisted of five zones including the ordinary four zones: the zona glomerulosa, the zona intermedia, the zona fasciculata, the zona reticularis, and in addition to these, a characteristic juxta-medullary zone which was observed inside the zona reticularis. This type of cortex was mainly found in the hypothalamic lesioned rat which succeeded in rearing, and the sham operated rat. The adrenal cortex of the second type consisted of the zona glomerulosa, the zona intermedia, the zona fasciculata and the zona reticularis. The demarcation between the zona fasciculata and the zona reticularis was not 
clear. The zona reticularis of this type was very wide and looked like the juxta-medullary zone of the first type. The adrenal cortex of this type was found in the lesioned rat which failed in rearing. Most of the lesioned, lactating rats replaced with oxytocin also had adrenals which belonged to this type.

In the group of the lesioned, rearing-succeeded rat, the first type of the adrenal cortex was found (Fig. 1). The zona intermedia composed of cuboidal cells with small darkly stained nuclei was a narrow band and lay between the zona glomerulosa and the zona fasciculata (Fig. 4). Cytoplasm of the cell in the zona glomerulosa was poorly stained and filled with small vacuoles. The zona fasciculata was the widest zone in the cortex and was mainly composed of enlarged and extensively vacuolated cells. In the inner portion of the zona fasciculata, however, cells were poorly vacuolated and slightly smaller than those in the outer portion. The zona reticularis was a very distinctive and narrow layer where cells were small and contained a little cytoplasm with fow vacuoles (Fig. 5). In addition to the zones described above, a peculiar zone was found inside the narrow zona reticularis. The cells in this zone were moderate in size and the cytoplasm contained few or no vacuoles, but contained occasionally granules. It should be reasonable to refer this zone to the juxta-medullary zone or the interlocking zone from its locus close to the medulla and the appearance of cells.

Histological appearance of adrenals in the sham operated rat was quite similar to that in the lesioned, rearing-succeeded rat.

In the group of the lesioned, rearing-failed rat (Group 2), no appreciable difference in appearance of both the zona glomerulosa and the zona intermedia was found, comparing with that in Group 1 (Figs. 4 and 6). The zona fasciculata of Group 2 was wider to some extent than that found in Group 1. This might be due rather to vacuolation of the cells and an increase in average cell size than to an increase in cell number of the zone (Fig. 2). Contrary to Group 1, it must be noted that the cells of the inner portion of the zona fasciculata in this group were not smaller than those of the outer portion.

A zone consisting of less vacuolated cells was found between the zona fasciculata and the medulla, though a boundary between these two zones was obscure (Fig. 7). This zone was the zona reticularis s. latiori and looked somewhat basophilic when $\mathrm{M}$ a 1lo ry's azan method was used. The size of the cells in this zone was larger than those in the zona reticularis found in the rearing- 
succeeded and the sham operated rats, though it varied from animal to animal. In some animals of this group, in contrast to the usu tendency that the size of cells became smaller and smaller from the outer portion of the zona fasciculata inwards to the medulla, it became slightly larger again from the inner zona fasciculata to the innermost layer. Therefore, the size of cells in the innermost layer was larger than that in the zona reticularis found in the adrenal cortex of Group 1. Appearance of these cells in this zone, in respect of their large size and little vacuolation in cytoplasm, was similar to that for the juxta-medullary zone in Group 1. However, a large amount of connective tissue which was a characteristic feature of the zona reticularis was found around these cells.

Although no clearly demarcated zona reticularis consisting of small sized cells, which were found in the zona reticularis of the adrenal in the lesioned, rearing-succeeded rat could be observed in most animals that failed in rearing, a trace of the zona reticularis s. strictori could be found in the innermost portion of the zona fasciculata in a few animals which failed in rearing (Group 2).

It could be said, therefore, that the adrenal cortex of this group was composed of the zona glomerulosa, the zona intermedia and the strikingly wide fasciculo-reticular zone.

Histological appearance of the adrenal gland in Group 3, the group of lesioned, oxytocin-replaced rats (Figs. 3, 8 and 9), was quite similar to that in Group 2 with a few exceptions in which the appearance of the adrenal cortex resembled that in Group 1.

\section{Discussion}

Since there are no significant differences both in weight of adrenal glands and in histological appearance between the lesioned, rearing-failed rat with oxytocin replacement (Group 3) and those without oxytocin treatment (Group 2), increase in the weight and hypertrophy of the inner cortex are considered to be a result of the hypothalamic lesions, causing failure of lactation and not due to the oxytocin replacement. In the lesioned, rearing-succeeded group (Group 1), adrenal weight was smaller than that in the lesioned, rearing-failed group. Therefore, it can be assumed that the lesions resulting in failure of lactation are responsible for increase in adrenal weight. These observations are inconsistent with those reported by $\mathrm{G}$ a le et al. (1961) that lactational performance was directly related to adrenal size in lactating rats with hypothalamic lesions. 
It has been known that deficiency of ACTH results in decrease in adrenal weight and that increase in adrenal weight is used for the assay of ACTH (F is he r. 1962). However, an assumption, that increase in weight of adrenals in the rat which failed in rearing was caused by increase in ACTH release may not be acceptable. Subnormal milk obtained from the lesioned, rearing-failed rat by oxytocin replacement seems to be due to deficiency of corticoid secretion, since nearly normal pregnancy and delivery which seemed to be an evidence for an unimpaired gonadotrophin-prolactin system took place in the lesioned rat. Since there have been no physiological investigations for evaluating the release of ACTH in the lesioned rats, further studies are required for the final conclusion concerning the cause of change in adrenal weight.

It is reasonable to conclude from the histological observations that increase in adrenal weight found in the lesioned, rearing-failed rat with or without oxytocin replacement can be attributed to a striking hypertrophy of the inner cortex. The inner cortex in these hypertrophied adrenals is composed of two layers; one of which is the somewhat hypertrophied, inner zona fasciculata and the other is located inside the former. The latter layer is not clearly demarcated from the inner zona fasciculata and contains less vacuolated cells which are larger than those in the zona reticularis in the rearingsucceeded rat. Since the innermost layer of the adrenal cortex of these animals can be regarded either as an inner portion of the zona fasciculata from the cytological point of view or as a part of the zona reticularis on the basis of distribution of the connective tissues, the adrenal cortical layer excluding the zona glomerulosa and the zona intermedia should be named "fasciculo-reticular zone."

The juxta-medullary zone observed in the adrenal cortex of the lesioned, rearing-succeeded rats has been reported to exist in rats by a few workers only. The juxta-medullary zone is situated inside the zona reticularis and the cell type of this zone is different from that of the zona reticularis. This zone was often called interlocking zone. N i c a nde $\mathrm{r}$ (1952) reported in rats that the juxta-medullary zone was distinguished from the zona reticularis by its larger and more eosinophilic cells with larger nuclei and no pigment or vacuole in their cytoplasm. $\mathrm{Hunt}$ and $\mathrm{Hunt}$ (1959) observed that the. juxta-medullary zone was most obvious in rats between 23 and 42 days of age, but absent in older rats and the zone was characteristically devoid of glycogen. A nderse $\mathrm{n}$ and $\mathrm{Ke} n \mathrm{nedy}$ (1932) and $\mathrm{H}$ ow a $\mathrm{r}$ (1938) found that there were small groups of cells which 
were larger than the reticular cells and had strongly eosinophilic cytoplasm. How a r d (1938) considered that they were derived from the juvenile cortex most of which gradually transformed into the adult zona reticularis. On the other hand, $A \mathrm{n} d$ e r se $\mathrm{n}$ and $\mathrm{Ke} \mathrm{n}$ $\mathrm{nedy}$ (1932) reported in the estrous rat that these cells were enlarged in size and contained more vacuoles in cytoplasm, and resembled those of the outer portion of the zona fasciculata. The present findings that a continuous layer of large rounded cells with eosinophilic cytoplasm was observed inside the zona reticularis were in accord with that reported by $\mathrm{Bacsich}$ and Folle y (1939) in lactating rats, who proposed to call these cell " $\mathrm{Y}$ " cells. Cytological observation of the cell in the juxta-medullary zone reported here, suggests that this zone should be distinguished from the zona reticularis, although distribution of the connective tissue surrounding these cells was similar to that found in the zona reticularis of normal rats.

The cell of the innermost layer of the fasciculo-reticular zone found in the lesioned rats which failed in rearing was similar to that of the juxta-medullary zone in respect of its large size and less vacuolation. However, these two zones were different from each other in tinctorial affinity; a little basophilic in the former, while strongly eosinophilic in the latter. A large amount of connective tissue in the innermost layer was alike to that found in the zona reticularis of the cortex in the rearing-succeeded rats. In a few animals which failed in rearing, there was a trace of a zone consisting of the cells of the zona reticularis s. strictori. Therefore, it is reasonable to conclude, that the layer inside the zona fasciculata is to be derived from either the zona reticularis or the juxtamedullary zone or both, but not from the zona fasciculata, and to be called the zona reticularis s. latiori. However, these two zones should be put into one layer, the fasciculo-reticular zone, since no clear demarcation between the zona fasciculata and the zona reticularis s. latiori was found.

In order to explain the change in the inner layer of the adrenal cortex reported here, we should like to adopt Ton utti's (1941) conception, so called hypothesis of transformation fields of the adrenal cortex. It can be assumed, that the adrenal cortex in rats is composed of the basic four zones: the zona glomerulosa, the zona intermedia, the zona fasciculata and the zona reticularis. In such a physiological condition as lactation, a little elevation in demands for corticoids results in progressive transformation in the inner 
cortex which eventually forms the juxta-medullary zone located closely to the medulla.

To explain the presence of the wide fasciculo-reticular zone having no sharp demarcation between the zona fasciculata and the zona reticularis, there are two alternatives. In the first place, further rise of demand for corticoid results in the progressive transformation in all the inner layer of the cortex. In the second place, special lateral dedifferentiation takes place in the inner layer of the adrenal cortex. The fact that subnormal milk yield obtained in the lesioned rats which failed in rearing and replaced with oxytocin seems to be ascribed to deficiency or decrease in corticoid secretion which was caused by partially impaired ACTH secretion, and that fatty degeneration was observed in the lactating rat whose young was removed ( $\mathrm{Fujioka}$, unpublished) may support the second explanation.

\section{Summary}

The adrenal glands of the hypothalamic lesioned rats which failed in rearing their young were compared with those of the rearing-succeeded rats.

The adrenal gland was heavier in the lesioned rat which failed in rearing than in the one that succeeded in rearing. An administration of oxytocin to repair lactational performance to subnormal level, did not prevent the enlargement of the adrenal gland.

The adrenal cortex of the hypothalamic lesioned rat which succeeded in rearing had a juxta-medullary zone, in addition to the usual four zones: the zona glomerulosa, the zona intermedia, the zona fasciculata and the zona reticularis.

In the lesioned rat which failed in rearing, the adrenal cortex was composed of the zona glomerulosa, the zona intermedia and a wide fasciculo-reticular zone and there was neither a clear defined zona reticularis nor the juxta-medullary zone. Oxytocin administration had no effect on the histological appearance of the adrenal cortex in the lesioned rat which failed in rearing.

The fact that the adrenal gland was heavier in the lesioned rat which failed in rearing than in the one which succeeded in rearing could be attributed to the presence of the hypertrophied. fasciculo-reticular zone.

It may be suggested, that the presence of the wide fasciculo- 
reticular zone is explained by the special lateral dedifferentiatior taking place in the inner layer of the adrenal cortex.

\section{Literature cited}

A ndersen, D.H. and H.S. Kennedy, 1932. Studies on the physiology of reproduction. IV. Changes in the adrenal gland of the female rat associated with the oestrous cycle. J. Physiol., $76: 247-260$.

B a c s i c h, P. and S. J. F o 11 e y, 1939. The effect of oestradiol monobenzoate on the gonads, endocrine glands and mammae of lactating rats. J. Anat., 73 : 432-440.

Cow i e, A. T., 1961. The hormonal control of milk secretion. In : Milk: The mammary gland and its secretion ( $\mathrm{K}$ o n, S. K. and A. T. Cow i e, eds.). Acad. Press, New York and London, $1:$ 163-203.

Fisher, J.D., 1962. Adrenocorticotropin. In: Methods in hormone research (R. I. Do $\mathrm{f} f \mathrm{~m}$ a $\mathrm{n}$, ed.). Acad. Press, New York and London, 2: 641-669.

Gal e, C. C., S. T a l e i s n i k, H. M. Fried ma n and S. M. M c Ca n n, 1961. Hormonal basis for impairment in milk synthesis and milk ejection following hypothalamic lesions. J. Endocrin., 23 : 303-316.

$\mathrm{H} u \mathrm{n} t \mathrm{~T}$. E. and E. A. $\mathrm{Hunt}$ t 1959. Glycogen in the adrenal gland of rats at different ages. Anat. Rec., 133 : 537-552.

$\mathrm{Nic}$ a n e r, L., 1952. Histological and histochemical studies on the adrenal cortex of domesticated and laboratory animals. Acta Anat., Suppl. 16 ad $144: 1-88$.

To nutti, E., 1941. Hormonal gesteuerte Transformationsfelder in der Nebennierenrinde? Z. f. mikr.-anat. Forsch., $50: 495-501$.

Y o k o y a ma, A. and K. Ôta, 1959a. Effects of administration of oxytocin and prolactin on lactating activity of mammary glands in rats. Endocrinol. Japon., 6 : 259-267.

Y o k o y a ma, A. and K. Ôta, 1959b. Effect of oxytocin replacement on lactation in rats bearing hypothalamic lesions. Endocrinol. Japon., 6: 268-276.

Yok o y a ma, A. and K. Ôta, 1960. Studies on mammary glands of lactating rats bearing hypothalamic lesions. Endocrinol. Japon., $7: 1-7$.

\section{Explanation of figures}

All the materials were fixed in Boui n's solution and stained with Mallory's azan method.

\section{Plate I}

Fig. 1. Adrenal cortex of the lesioned, rearing-succeeded rat. Adrenal cortex was composed of the zona glomerulosa, the zona intermedia, the zona fasciculata, the zona reticularis and the juxta-medullary zone.

Fig. 2. Adrenal cortex of the lesioned, rearing-failed rat. Adrenal cortex consisted of the zona glomerulosa, the zona intermedia and the fasciculo-reticular zone.

Fig. 3. Adrenal cortex of the lesioned, oxytocin-replaced rat. Appearance of adrenal cortex was quite similar to that of the lesioned, rearing-failed rat. 


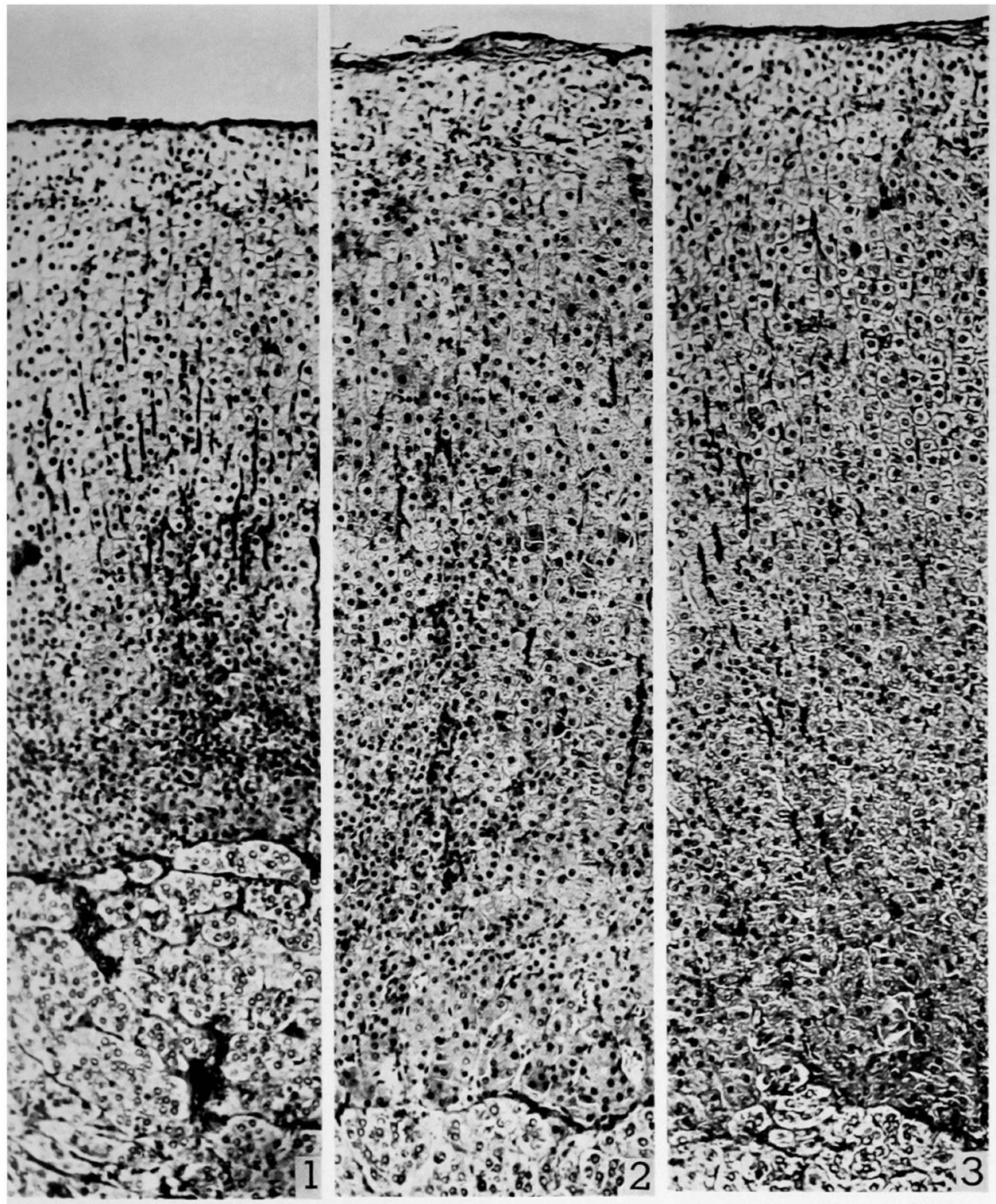




\section{Plate II}

Figs. 4, 6 and 8. Outer cortex of the lesioned, rearing-succeeded rat, of the lesioned, rearing-failed rat and of the lesioned, oxytocin-replaced rat, respectively. No significant difference can be detected.

Figs. 5, 7 and 9. Inner cortex of the lesioned, rearing-succeeded rat, of the lesioned, rearing-failed rat and of the lesioned, oxytocin-replaced rat, respectively. In Fig. 5 the zona reticularis and the juxta-medullary zone can be seen. 

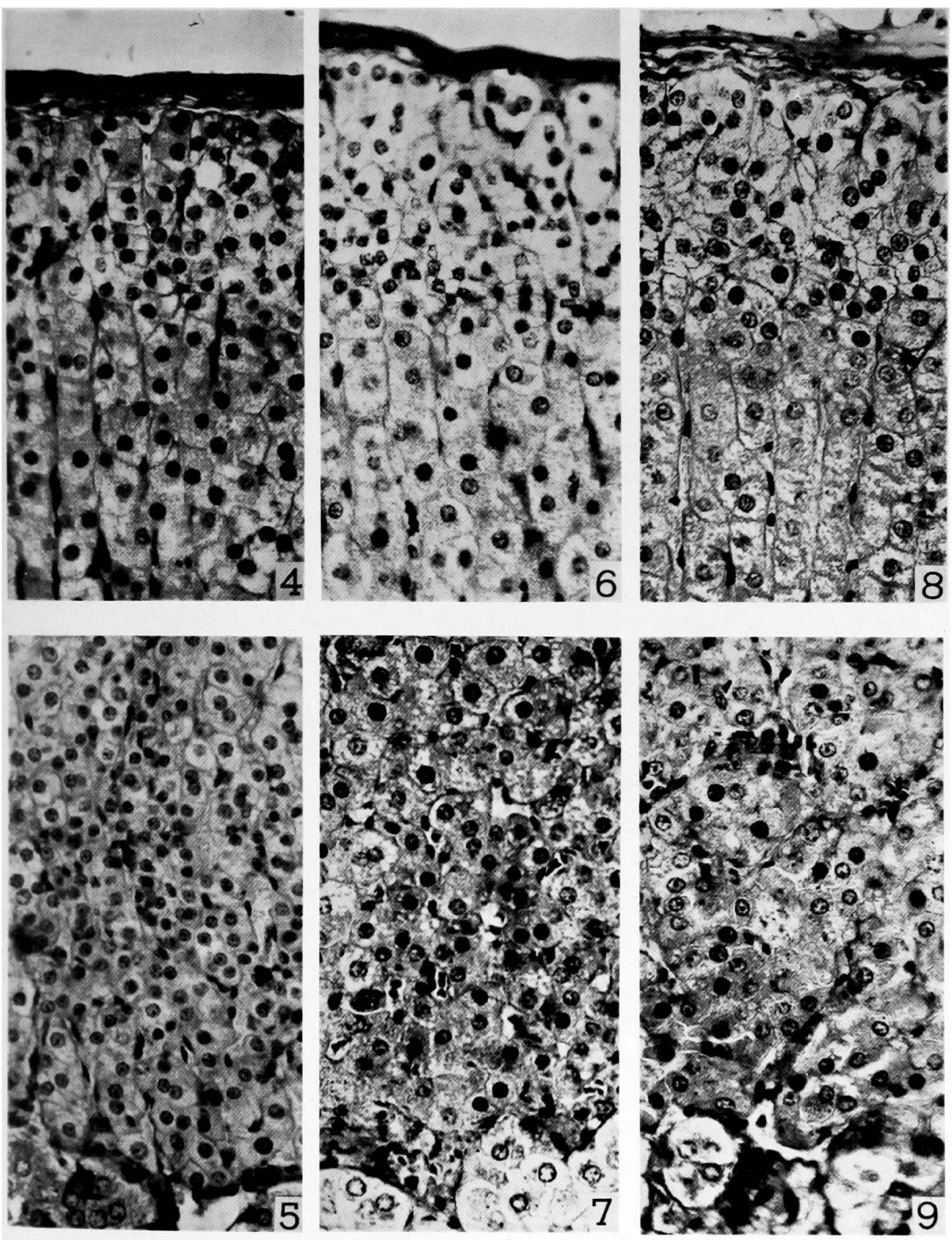

T. Fujioka, K. Ôta and A. Yokoyama 